\title{
Closed and Open Design Projects in the Education of Engineers
}

\author{
Franksen, Ole Immanuel
}

Published in:

IEEE Transactions on Power Systems

Link to article, DOI:

10.1109/TPAS.1965.4766182

Publication date:

1965

Document Version

Publisher's PDF, also known as Version of record

Link back to DTU Orbit

Citation (APA):

Franksen, O. I. (1965). Closed and Open Design Projects in the Education of Engineers. IEEE Transactions on Power Systems, 84(3), 228-231. https://doi.org/10.1109/TPAS.1965.4766182

\section{General rights}

Copyright and moral rights for the publications made accessible in the public portal are retained by the authors and/or other copyright owners and it is a condition of accessing publications that users recognise and abide by the legal requirements associated with these rights.

- Users may download and print one copy of any publication from the public portal for the purpose of private study or research.

- You may not further distribute the material or use it for any profit-making activity or commercial gain

- You may freely distribute the URL identifying the publication in the public portal

If you believe that this document breaches copyright please contact us providing details, and we will remove access to the work immediately and investigate your claim. 


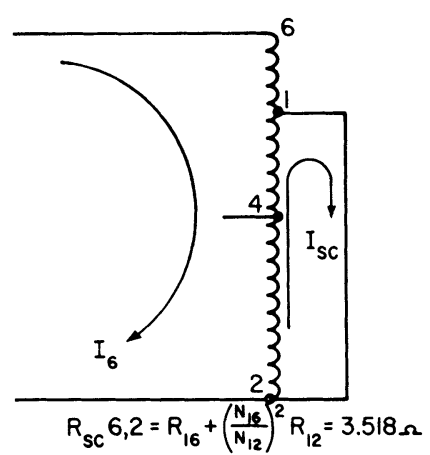

Fig. 6 (left). Circuit for calculation of $R_{\mathrm{sc}} \mathbf{6 , 2}$
In the previously mentioned expression, the two primary windings of Fig. 7 are $N_{42}$ and $N_{14}$. The short-circuited secondary winding is $N_{12}$. The two portions of the secondary resistance reflected into the primary circuit are $R_{42}$ and $R_{14}$. There is no independent primary winding resistance as in Fig. 6.

\section{Appendix II. Formula for Metering Error}

\section{Var Metering}

True vars $=V I \sin \theta$

Measured vars $=\frac{1}{\mathrm{RCF}} V I \sin (\theta+\alpha)$

$$
=\frac{1}{\mathrm{RCF}} V I(\sin \theta \cos \alpha+\cos \theta \sin \alpha)
$$

For small angles $\cos \alpha=1$ and $\sin \alpha=\alpha$ (in radians), however, Measured vars $=\frac{1}{\mathrm{RCF}} V I(\sin \theta+\alpha \cos \theta)$

Error in vars per unit $=\frac{\frac{1}{\mathrm{RCF}} V I(\sin \theta+\alpha \cos \theta)-V I \sin \theta}{V I \sin \theta}$
Fig. 7 (right). Circuit for calculation of $\mathbf{R}_{\mathrm{sc}} \mathbf{4 , 2}$

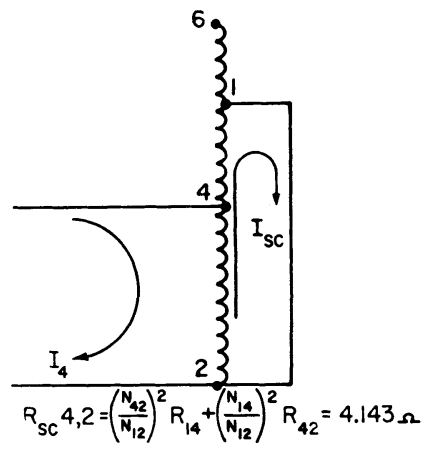

Error in vars per unit $=\frac{1}{\mathrm{RCF}}(1+\alpha \cot \theta)-1$

With further manipulation,

Error in vars per unit $=\frac{1}{\mathrm{RCF}}[(1-\mathrm{RCF})+\alpha \cot \theta]$

Voltampere Metering

Voltamperes $=\sqrt{\text { watts }^{2}+\text { vars }^{2}}$

If the watts are measured correctly, the error in voltamperes caused by the error in vars may be calculated.

$V I($ meas $)=\sqrt{(V I \cos \theta)^{2}+\left[V I \frac{1}{\mathrm{RCF}}(\sin \theta+\alpha \cos \theta)\right]^{2}}$

Per unit error in voltamperes $=\frac{V I(\text { meas })-V I}{V I}$

$$
=\sqrt{(\cos \theta)^{2}+\left[\frac{1}{\mathrm{RCF}}(\sin \theta+\alpha \cos \theta)\right]^{2}}-1
$$

\title{
Closed and Open Design Projects in the Education of Engineers
}

\author{
Ole I. Franksen, Member IEEE
}

\begin{abstract}
The two aspects of engineering education are the teaching of science and the teaching of design. By "design" is meant the procedure of selecting and combining distinct elements to create complete systems which will perform useful functions. In this paper, the author describes the application of this concept of design teaching at The Technical University of Denmark, after a procedure which includes a sequence of closed and open design projects in both computational and experimental laboratories.
\end{abstract}

\section{Closed and Open Design Projects}

After the engineering student has absorbed and learned how to use some scientific knowledge, he undertakes the study of design. To do this, he is provided with an array of separate materials and parts (the "primitive system") and asked to select some of these elements and to combine them suitably into either a simple piece of equipment or a more complex aggregate. The initial projects should be of the closed design type, in which the total primitive system is fixed in advance. In the final stages of his education, the engineer should be asked to solve the more difficult open design problems, in which some or all elements of the primitive system are developed during the design process.

\section{The System Concept}

To accomplish his purposes, the engineer must be able to describe the external world and the objects it contains in

Paper 31 TP 65-149, recommended and approved by the Power Engineering Education Committee of the IEEE Power Group for presentation at the IEEE Winter Power Meeting, New York, N. Y. January 31-February 5, 1965 . Manuscript submitted September 10, 1964; made available for printing December 9, 1964.

O. I. Franksen is with the Electric Power Engineering Department, The Technical University of Denmark, Lyngby, Denmark. 
definite and distinctive terms. It is common sense that an object, to be identifiable, must be a discrete thing separated from its surroundings by discontinuities which persist in either space or time; it must be a thing, moreover, which has distinct and independent properties. Thus, most engineering products can be perceived as identifiable objects.

The engineer who is to design and build a project cannot regard it as a black box, a phenomenon; he must consider each given product as an aggregate of identifiable objects bounded by certain discontinuities. The identifiable objects are generally termed elements, while the aggregate is called a system. Since elements are discrete objects, each with its independent properties, they are normally recognized as phenomena.

The designation of an element in any chosen system is arbitrary. In a given project, the engineer may combine the elements into a few more complex objects called subsystems, or he may resolve them into a larger number of less complex objects called components. The relations among components, elements, subsystems, and the complete system are like the relations among Chinese boxes. When mathematically expressed, these relations are recursive.

The properties of a product which has been identified as a system by virtue of its discontinuities with its environment are given as functions of the properties of each of the isolated elements, on the one hand, and, on the other hand, as functions of the manner in which the distinct elements are interconnected to form the system.

When the engineer is building or using a system, he is aiming at a desired interaction between the system and its environment. He regards this interaction as a function of the system properties produced by a specified set of external influences impressed upon the system. The interaction may be expressed in terms of either states of the system or flows through it, according to the scope of the project to be carried out.

\section{The Design Concept}

The engineering function of design may be defined as the procedure, based upon certain criteria, in which basic principles are used to realize a system which will satisfy specified requirements, when subjected to a given set of impressed external influences.

Four steps are usually taken in designing a system, whether it is a machine, an apparatus, a plant, or a method:

1. The discontinuities between the proposed system and the impressed external influences are defined, then organized or structured in a way that will yield an outline of the system in terms of the relations between the desired interaction (states or flows) and the external influences.

2. A synthesis is performed by selecting appropriate elements and interconnecting them into a system.

3. An analysis determines whether the system decided upon satisfies the given requirements. The analysis can be either computational, if based upon a mathematical model established from theory, or experimental, if the developed system or its corresponding laboratory model is evaluated by tests.

4. An optimization is performed, since a normal design problem does not have a unique solution. Certain criteria, such as minimum cost or minimum weight, are used to determine from what part in the solution-space the system-configuration must be chosen for best compliance with the given requirements.

Thus, design consists of selecting from available elements and then interconnecting these selected elements into a system. The aggregate of distinct elements (construed as phenomena with known properties) from which the systemelements are to be selected is the basis of the design process. This aggregate is designated the primitive system, an analogy to Gabriel Kron's electric network concept. The process of designing a primitive system and the rules for the possible manners of interconnection are called standardization if the criteria applied are oriented toward optimizing the total of the many different systems to be designed from the primitive system in question.

The establishment of international norms and standards for rotating electric machinery is standardization aimed at building up a primitive system in accord with customer wishes. The elements are specific machines regarded as phenomena with known properties such as shaft height, horsepower, and speed. A motor manufacturer, on the other hand, interprets international norms and standards as fixed requirements to be met by his designs. To him, standardization (often termed internal standardization) is the development of the single parts of the machines to be manufactured in a way which will minimize the overall production cost.

Depending upon the way in which the primitive system is defined, i.e., the availability of distinct elements, two types of design problems may be distinguished. When the total primitive system is fixed in advance, it is a closed design problem. When the primitive system, or parts of it, are developed during the design process, it is an open design problem.

Closed design problems are typical in the manufacture of standardized products in the apparatus industries, while open design problems are typified by the building of bridges, large ships, and electric power plants. The latter are usually one-time problems.

\section{The Education of Engineers}

The aim of engineering education is to bridge the gap between the acquirement of scientific knowledge, as presented in lectures, and the solution of the practical multiple-answer industrial problems the student will meet during his professional career. The student must be taught an engineering way of thinking, in order that he may visualize structures, make engineering judgments, realize the need to compromise, and be able to cope with both abstractions and tangible things.

The student should acquire skills which will enable him to recognize and define an engineering multiple-answer problem, to plan its method of solution, to execute the required computations and experiments, to verify the solution he has obtained and, finally, to present the results either orally or in writing. He should be able to do all this in a systematic, expedient, and practical way.

A student learns only by what he does. Therefore, he must perform projects on his own initiative, building up systems from elements by successive approximations, in computational and experimental laboratories. Since a student learns most readily by proceeding from the specific to the general and by solving simple problems before approaching difficult ones, it is necessary to arrange a sequence of laboratory projects which will challenge him with 1) problems of analysis, 2) closed design problems, and 3) open design problems.

The engineering analysis problems to be solved by computation should familiarize the student with applications of the theory developed in the classroom. Similar problems solved experimentally, with laboratory equipment used in prespecified ways, provide the student with the basic skills and techniques of measurement. The characteristic feature of these analytical problems, presented in both kinds of laboratories, is that they usually have unique solutions. 
On the other hand, closed or open design problems have multiple answers. Here the student is told what is wanted but not how he is to do it. By starting with projects of the closed design type with relatively few elements in the primitive system; then continuing with projects having gradually more extensive primitive systems; and, finally, presenting open design problems (where the number of elements in the primitive system is unlimited), the student exercises progressively more freedom; he is required to make more decisions, to do more planning, and to use greater skill in performing his assignment.

To motivate the students and to arouse their interest, closed and open design projects should be stated in terms of engineering reality. They should be based on the results of industrial experience, or should utilize practical machines and apparatus which can be taken apart or changed in material ways. The university grading system should take into account the importance of computational and experimental laboratory work, in association with the study of theory, in order that the working loads of the two sides of his education may seem fairly balanced to the student.

The use of closed design problems as an intermediate step in laboratory projects provides economies in teaching, because it is relatively easy to compare and evaluate the different student responses to these simple problems. Moreover, inexperienced instructors can take effective charge of this kind of student project, under the supervision of one or a very few experienced staff members.

The chief problems in developing a computational or experimental laboratory closed design project are the choice and procurement of those elements of the primitive system with which the students will work. The primitive system should be large enough to give the student the impression that he is working with a genuine problem in engineering design and to subject him to all the difficulties, delays, and frustration typical of such problems; also, it should be sufficiently limited to permit the teacher to guide and inspire the students with a reasonable amount of time and effort.

\section{Problems in the Electric Power Engineering Field}

In the universities, the subject of electric power must compete with electronics, computer design, solid-state physics, nucleonics, and other newly important topics for the interest of students. The result has been that, everywhere, power engineering courses have been curtailed or dropped altogether [1].

The only way to reverse this trend would be to motivate bright students to study and work in the power field. The author believes this can be done if the universities are willing to take the necessary steps and if they have the support of the electric power industry. In view of the vast extent and importance of electric power supply, it seems worthwhile to move in this direction.

It is of primary importance, in power option courses, to recognize the great influence of digital computers on both theory and the computational aspects of design; this influence dates back to the first industrial transformer designs some twelve years ago. Traditionally, the design of electric machinery has been taught as a "cook book" course, which left little to the imagination or to the judgment of the students and was unrelated to other engineering design fields.

It should be realized that electric machine design problems are now chiefly of the closed type, so that computers may take over synthesis and optimization as well as the analysis phase [2]. Therefore, students should be greatly interested in well- planned electric machinery design projects in the computational laboratory if these are presented as the foundation for a later advanced course in design by digital computers [3], [4]. A basic purpose in such courses should be to give the students the ability to subdivide a problem into its many component parts.

Usually, computers can be used only in the analysis phase of planning and utilizing electric power utility networks, since these are normally open design problems [2]. However, the development of the macroprogramming languages [5] has provided powerful new methods for using computers on a wide range of problems. The wide perspective for system studies inherent in Gabriel Kron's theories also provides inspiration for the best students. It seems clear that the system and interconnected-circuit viewpoints traditionally associated with electric power are a growing trend in engineering education.

For system-oriented projects in the experimental laboratory, "kits" of machine parts and relatively inexpensive and diverse items and apparatus should be provided [6]-[9]. Every effort should be made to provide interesting new materials and devices; the students should be free to invent and develop projects of their own. The project laboratory of this type developed at Rensselaer Polytechnic Institute [7] is an example of what may be done to encourage the interest of good students. Here, Alnico, Lodex, Saturistors, and silicon rectifiers were used in association with a variety of small rotating machines and the Emmerling torque transducer. However, the support of the power industry is essential, if laboratory projects of the open design type are to be carried through, year after year, with new ideas.

\section{Electric Machinery Design Laboratory}

During the past 4 years, a computational laboratory course in closed design problems has been offered as part of the curriculum at The Technical University of Denmark. This course, which extends over 24 4-hour sessions, is within the field of electric machinery and industrial power systems but is graded separately.

The introductory project in the course is the design of a power transformer to customer specifications; this provides the student with a typical closed design problem. At the start of the course, he is given a sheet stating 1) the rating of the transformer to be designed, 2) the short-circuit reactance, 3) the preferred ratio of load-to-no-load losses, and 4) a standard practice book [10] giving all the elements of the primitive system. It is then the student's responsibility to arrange the computations and select those elements of standard practice necessary to determine, by cut-and-try methods, the most economical transformer design for the given requirements.

The standard practice book gives instructions in ten groups; these instructions contain the rudiments for solving detailed design problems and specify costs plus the materials for the magnetic circuit, insulation, windings, losses, reactance and forces, tank and radiators, and bushings and tap changers.

A vital part of the project is a visit to one of the local power transformer factories. Here the students can observe, in detail, the manufacture of the kind of power transformers they are to design and discuss their problems with experienced designers. The cooperation of the power industries in arranging these visits is a helpful means of inspiring the students.

At the end of the project, the students hand in filled-out design sheets with short reports on what they have done. Although this project requires a great deal of work, the students have been deeply interested because it challenges their creative abilities. To tell the students the results im- 
mediately and to show them the scope of what they have learned, a digital computer program has been developed for the IBM 7074 computer, by which the students' answers can be automatically corrected by reading the figures on the design sheets into the computer. At the end of the course, there is a concluding discussion on how to carry out electric machinery design on digital computers.

\section{Experimental Laboratory Projects}

The Rensselaer Polytechnic Institute Projects Laboratory [7]-[9] offers problems chiefly of the open design type, with ac machines such as those regularly used in power systems. It is expected that further developments in this laboratory will introduce closed design projects, as well.

The work carried on at The Technical University of Denmark in developing closed design problems centers on the design of standardized control elements and the apparatus to be used with de machines, such as those used in paper mills.

The writing of instructions for students, the students' recording of data, and their reports on what they have accomplished are all important features of the experimental laboratory. Laboratory instructions are prepared in two distinct forms. One of these contains instructions for measuring techniques and the instruments and devices to be used; the other form treats the procedure and features of the apparatus used in specific projects.

Students are expected to have their plans of approach to a project approved before they start work in the laboratory. Each student also keeps an engineering notebook [11][13].

\section{Conclusion}

In the past two decades, a chief feature of engineering education has been the growing emphasis on the teaching of science, with a seemingly never-ending subdivision into unrelated specialties. Of course, engineers as well as scientists should be educated in the use of scientific methods. However, when the engineering curriculum is exclusively devoted to science, without recognition that the ultimate purpose of engineering is design, then the time has come for a change.

The purpose of a technical university or college is to provide society with engineers, not pseudoscientists. To inspire firstrate young men to undertake engineering careers, it is necessary to emphasize this. The educational program must strike a proper balance between the teaching of science and the teaching of engineering.

For the engineer, knowledge and an understanding of natural phenomena are not ends in themselves, but are the means to designing useful systems. Therefore, the educator, by utilizing the widely applicable concepts of modern mathematics, should strive to unify the numerous unrelated specialties into simple interdisciplinary structures. Moreover, he should appreciate the growing importance of digital computers in solving engineering design problems.

Because design is the essence of engineering, it should be the keystone of an engineering education [14]-[16]. Although various aspects of engineering design may be reduced to formal disciplines, design will remain an art which can be mastered only by actual practice. The roles of computational and experimental projects laboratories are to bring learningby-doing into the engineering curriculum. It is believed that the stepwise approach, in terms of the sequence of closed and open design problems advocated in this paper, is a desirable way of accomplishing the aim.

\section{References}

[1] Dwon, L., Forces influencing engineering education from power, IEEE Trans. on Power Apparatus and Systems, vol 83, Aug 1964, pp 826-855

[2] Franksen, O. I., and M. D. Roemer, The uses of computers in industrial production, Ingenioeren, vol 73, Apr 15, 1964, pp 257-264 (in Danish)

[3] Franksen, O. I., and M. D. Roemer, The properties of the digital computer-valued with regard to engineering uses, ibid., vol 72, Feb 1, 1963, pp 117-132 (in Danish)

[4] Franksen, O. I., and M. D. Roemer, Information and digital computers-based on the redundancy concept, ibid., Apr 1, 1963, pp 243-260 (in Danish)

[5] Franksen, O. I., The uses of macroprogramming languages in power system design and operation, presented at the Conf. on Analytical Methods for Power System Design and Operation for Use with Digital Computers, Queen Mary College, Univ. of London, England, Sep 1963

[6] Blackwell, W. A., and H. E. Koenig, A combined machinery and control systems laboratory, IRE Trans. on Education, vol E-2, Sep 1959, pp 128-134

[7] Alger, P. L., and L. P. Winsor, A projects laboratory for engineering students, ibid., vol E-6, Sep 1963, pp 9-12

[8] Emmerling, A. A., A torque measurement transducer system, Elec. Engrg., vol 82, Oct 1963, pp 621-625

[9] Alger, P. L., J. H. Charkow, and J. Davis, The RPI dynamic circuits laboratory-stepless A-C motor speed control and other projects, presented at the Conf. on Modern Electric Machine Theory, Univ. of Wisconsin, Madison, Wis., Apr 23-24, 1964

[10] Franksen, O. I., Transformatoren-Beregningsinstruktioner Copenhagen, Denmark: The Technical Univ, of Denmark, 1961

[11] Schwartz, R. F., Laboratory: its scope and philosophy, IRE Trans. on Education, vol E-2, Sep 1959, pp 120-122

[12] Kent, G., and W. H. Card, An experiment in laboratory education, ibid., vol E-4, Jun 1961, pp 62-66

[13] Allen, P. S., A coordinated laboratory program, ibid. (Correspondence), vol E-6, Sep 1963, p 34

[14] Committee on Engineering Design of M.I.T., Report on engineering design, J. Engrg. Educ., vol 51, Apr 1961, pp 645-660

[15] Kent, G., Education in experimental engineering, Proc. 1961 Syracuse Univ. Internat'l Conf. on Elec. Engrg. Educ., Sep 1961, pp 238-244

[16] Murphy, A. T., Development and design projects-a culmination, ibid., pp 245-253 